\title{
A Population-based survey of the prevalence and types of glaucoma in Nigeria: results from the Nigeria National Blindness and Visual Impairment Survey
}

Fatima Kyari ${ }^{1,2^{*}}$, Gabriel Entekume ${ }^{3}$, Mansur Rabiu ${ }^{4}$, Paul Spry ${ }^{5}$, Richard Wormald ${ }^{1,6}$, Winifred Nolan ${ }^{6}$, Gudlavalleti V. S. Murthy ${ }^{1,7}$, Clare E. Gilbert ${ }^{1}$ and On behalf of the Nigeria National Blindness and Visual Impairment Study Group

\begin{abstract}
Background: Glaucoma is the leading cause of irreversible blindness worldwide. There tends to be a lower reporting of glaucoma in Africa compared to other blinding conditions in global burden data. Research findings of glaucoma in Nigeria will significantly increase our understanding of glaucoma in Nigeria, in people of the West African diaspora and similar population groups. We determined the prevalence and types of glaucoma in Nigeria from the Nigeria National Blindness and Visual Impairment cross-sectional Survey of adults aged $\geq 40$ years.

Methods: Multistage stratified cluster random sampling with probability-proportional-to-size procedures were used to select a nationally representative sample of 15,027 persons aged $\geq 40$ years. Participants had logMAR visual acuity measurement, FDT visual function testing, autorefraction, A-scan biometry and optic disc assessment. Participants with visual acuity of worse than $6 / 12$ or suspicious optic discs had detailed examination including Goldmann applanation tonometry, gonioscopy and fundus photography. Disc images were graded by Moorfields Eye Hospital Reading Centre. Glaucoma was defined using International Society of Geographical and Epidemiological Ophthalmology criteria; and classified into primary open-angle or primary angle-closure or secondary glaucoma. Diagnosis of glaucoma was based on ISGEO classification. The type of glaucoma was determined by gonioscopy.

Results: A total of 13,591 participants in 305 clusters were examined (response rate $90.4 \%$ ). Optic disc grading was available for 25,289 (93 \%) eyes of 13,081 (96\%) participants. There were 682 participants with glaucoma; a prevalence of $5.02 \%$ (95\% Cl 4.60-5.47). Among those with definite primary glaucoma that had gonioscopy $(n=243)$, open-angle glaucoma was more common ( $86 \%$ ) than angle-closure glaucoma ( $14 \%) .8 \%$ of glaucoma was secondary with the commonest causes being couching (38\%), trauma (21\%) and uveitis (19\%). Only $5.6 \%$ (38/682) of participants with glaucoma knew they had the condition. One in every 5 persons with glaucoma $(136 ; 20 \%)$ was blind i.e., visual acuity worse than 3/60.

(Continued on next page)
\end{abstract}

\footnotetext{
* Correspondence: Fatima.Kyari@lshtm.ac.uk

'International Centre for Eye Health (ICEH), Clinical Research Department, London School of Hygiene and Tropical Medicine (LSHTM), Keppel Street, London WC1E 7HT, UK

${ }^{2}$ Department of Ophthalmology, College of Health Sciences (CHS), University of Abuja, Abuja, Nigeria

Full list of author information is available at the end of the article
} 
(Continued from previous page)

Conclusion: Nigeria has a high prevalence of glaucoma which is largely open-angle glaucoma. A high proportion of those affected are blind. Secondary glaucoma was mostly as a consequence of procedures for cataract. Public health control strategies and high quality glaucoma care service will be required to reduce morbidity and blindness from glaucoma.

Keywords: Prevalence, Glaucoma, Epidemiology, Nigeria, Open-angle glaucoma, Angle-closure glaucoma

\section{Background}

Glaucoma is the second leading cause of blindness worldwide and the leading cause of irreversible blindness, accounting for $8 \%$ of all blindness, affecting an estimated 3.12 million blind people [1]. A review of relevant population-based surveys of glaucoma, and of blindness and visual impairment in sub-Saharan Africa indicate that glaucoma affects about $4 \%$ of adults aged 40 years and above and accounts for $15 \%$ of blindness [2-4]. Africa is the region with the highest incidence and prevalence of glaucoma, most of which is open-angle glaucoma (OAG) $[5,6]$, and OAG is more prevalent in the black populations of Africa and Africa-derived populations [7]. Reports also suggest that the most difficult problematic OAG that there is in terms of severity of disease, difficulty in treating it and as a cause of blindness comes from West Africa $[2,3,8]$. Additionally, there tends to be a lower reporting of glaucoma in Africa compared to other blinding conditions in global burden data because surveys in Africa may have had limited diagnostic capacity for glaucoma [9]. The Nigeria national blindness and visual impairment survey (hereafter referred to as the Nigeria Blindness Survey), in which over 13,500 people aged 40 years and above were examined, is a populationbased survey that substantially addresses glaucoma prevalence and risk factors. The Nigeria Blindness Survey reported the prevalence of blindness to be $4.2 \%$ (95\% confidence interval 3.8-4.6 \%) [10], $16.7 \%$ being due to glaucoma [11]. Glaucoma was the leading cause of irreversible blindness [11] and functional low vision [12].

A standard definition and classification system for glaucoma in prevalence surveys proposed by the International Society of Geographical and Epidemiological Ophthalmology (ISGEO) [13] allows comparison of glaucoma prevalence surveys, further highlighting the variation between populations. Whereas angle-closure glaucoma is more frequent among east Asian populations $[6,14]$, the black populations of USA [15] the Caribbean [16, 17], and Africa [6, 18-22] have the highest prevalence of open-angle glaucoma with up to $90 \%$ of those affected being unaware that they have the condition [18, 21, 22].

In this study, data from the Nigeria Blindness Survey were analyzed using ISGEO criteria to determine the prevalence and types of glaucoma, to provide data for advocacy, policy and to plan services for glaucoma. However, the ISGEO classification system is not for clinical diagnosis or for assessment for treatment of glaucoma. The percentile values for the vertical cup:disc ratio (VCDR), VCDR asymmetry and intraocular pressure (IOP) to define glaucoma were derived from this study population. Possible risk factors for glaucoma in the population are presented in another paper.

Nigeria is the $7^{\text {th }}$ most-populous country in the world and had a total population of 128 million at the time of the national survey (January 2005 to June 2007). Nigeria has 6 main administrative/geo-political zones (GPZ): north-east (NE), south-east (SE), south-south (SS), north-west (NW), south-west (SW) and north-central (NC). Two-thirds $(63 \%)$ of the population live in rural areas. Nigeria has more than 250 ethnic groups, who live in different areas in the country each with their own language/dialects, customs and practices. The largest ethnic groups are the Hausa and Fulani in the north, Ibo in the south-east and Yoruba in the south-west. Despite recent economic development, adult literacy levels remain low (51\%), and $54 \%$ of the population live below the poverty line on less than a dollar a day [23].

There are insufficient population-based glaucoma studies in Africa to represent the entire continent in global glaucoma prevalence estimates [6]. From the few highquality surveys, it is difficult to extrapolate the findings to wider populations as they were conducted in limited and defined geographical areas of large countries [3]. This is the largest truly population-based study of glaucoma in Africa. Estimating the magnitude of glaucoma in Nigeria is important because it sheds light on inter-ethnic and regional variations of OAG prevalence in the black populations of Africa, Caribbean and USA. It will also provide a baseline for planning delivery of care to glaucoma patients in Nigeria and in countries with similar socio-demographic and ecological characteristics in sub-Saharan Africa.

\section{Methods}

Details of all the methods used in the Nigeria Blindness Survey have been published [24] as well as data on the prevalence [10] and causes of visual impairment, blindness [11] and low vision [12]. 


\section{Ethics}

Ethical approval was obtained from the Ethics Committee of the London School of Hygiene \& Tropical Medicine and the Federal Ministry of Health, Nigeria. Oral informed consent was obtained from community leaders, heads of households and all participants. The study adhered to the tenets of the declaration of Helsinki. Persons with medical or eye conditions needing further assessment and treatment were referred to the nearest healthcare facility. Cataract blind participants were offered surgery after the survey had been completed in each zone.

\section{Sample size calculation and sampling strategy}

The sample size calculation was based on the following: target population (22.6 million); expected prevalence of blindness in persons 40 years and older (5\%); desired precision (0.5\%); design effect due to clustered sampling (2); $95 \%$ confidence level; and $85 \%$ response rate. The sample size was 15,375 after allowing for non-response in 310 clusters of 50 participants each. With assumed glaucoma prevalence of $5 \%$ [3], this sample size would also give a precise estimate of the prevalence of glaucoma and allow risk factors for OAG to be analysed.

Multi-stage sampling using probability in proportion to size was used to select a nationally representative sample. In each cluster the center of the village/ward was identified and the direction of enumeration determined by spinning a bottle. Individuals aged 40 years and above who had lived in the household for at least the preceding 3 months were enumerated until 50 individuals had been identified. Examination took place over two days in a temporary clinic set up in the community. Those unable to leave their homes (e.g., due to disability) were examined at home.

\section{Clinical teams and quality control}

Data were collected by two clinical teams each comprising of two ophthalmologists, one optometrist, two ophthalmic nurses, four enumerators and one interviewer. Quality assurance included field supervision by the team leader, daily review of data collection forms, frequent visits by the Project Manager (MR) and Project Epidemiologist (GVSM), inter-observer agreement studies, retraining of all team members before visiting each zone, and double data entry by two trained data entry personnel. Three of the four ophthalmologists and both optometrists comprising the clinical teams remained unchanged but different nurses were recruited for each zone in order to address language and cultural variations. A detailed protocol of all the methods was used in training and for reference.

\section{Data collection and clinical assessment}

Clinical assessment in relation to glaucoma is described below. The examination flow is shown in Fig. 1.

\section{All participants}

All participants had their personal and socio-demographic data recorded including their self-reported ethnic group as well as medical and ocular history, including a history of glaucoma. Height, weight and blood pressure (Omron) were measured. Presenting and best-corrected distant visual acuities (VA) were measured by an ophthalmic nurse with a reduced logMAR E-chart [25]. All participants also had automated refraction, frequency doubling technology (FDT) visual field testing (see below), A-scan biometry by the optometrist and a basic eye examination by the first ophthalmologist.

\section{Detailed examination}

The following participants underwent detailed eye examination by the second ophthalmologist [10, 24]: those with a presenting VA $<6 / 12$ in one or both eyes; VCDR $\geq 0.6$ in one or both eyes or VCDR asymmetry of $\geq 0.2$, or any retinal abnormality seen on non-dilated direct ophthalmoscopy. In addition, 1-in-7 participants also had the detailed examination regardless of their VA, with random blood glucose testing, to provide a 'normative' database. Detailed eye examination included slit-lamp examination (Zeiss SL 115 Classic Slit Lamp, Carl Zeiss Meditec AG Jena Germany), Van Herick's (VH) anterior chamber (AC) angle depth estimation [26], assessment for relative afferent pupil defect (RAPD), applanation tonometry (Goldmann), lens opacity grading using the World Health Organization (WHO) classification, fundus and optic disc examination with 60D aspheric condensing lens (Volk) and binocular indirect ophthalmoscopy (BIO; Keeler all-pupil) with a 20D lens, and digital fundus imaging with Zeiss Visucam Lite Desk Top Fundus Camera (Carl Zeiss Meditec AG Jena Germany) focused on mid-point between the optic nerve head and the macular region through a dilated pupil. All images were graded independently at the Moorfields Eye Hospital Reading Centre (MEHRC). Gonioscopy (Volk's 1-mirror non-flanged lens) was performed if the IOP was $\geq 20 \mathrm{mmHg}$, or VCDR $\geq 0.6$, or VCDR asymmetry $\geq 0.2$, or $\mathrm{VH}$ grades $0,1,2$. Central corneal thickness was not assessed.

\section{Visual field testing}

Visual field testing was performed with a Humphrey FDT visual field analyzer (Carl Zeiss Meditec AG Jena Germany). The FDT perimeter is a robust, portable, selfcontained unit that weighs less than $10 \mathrm{~kg}$ and has a selfcalibration procedure. It is generally inexpensive, easy to understand and quick to perform the test [27]: it takes about $45 \mathrm{~s}$ to complete a normal screening test and about $45 \mathrm{~s}$ for a normal threshold test. These features informed the choice of the FDT perimeter and were advantages considering the logistics of a large population-based survey of this kind where examinations were carried out in 


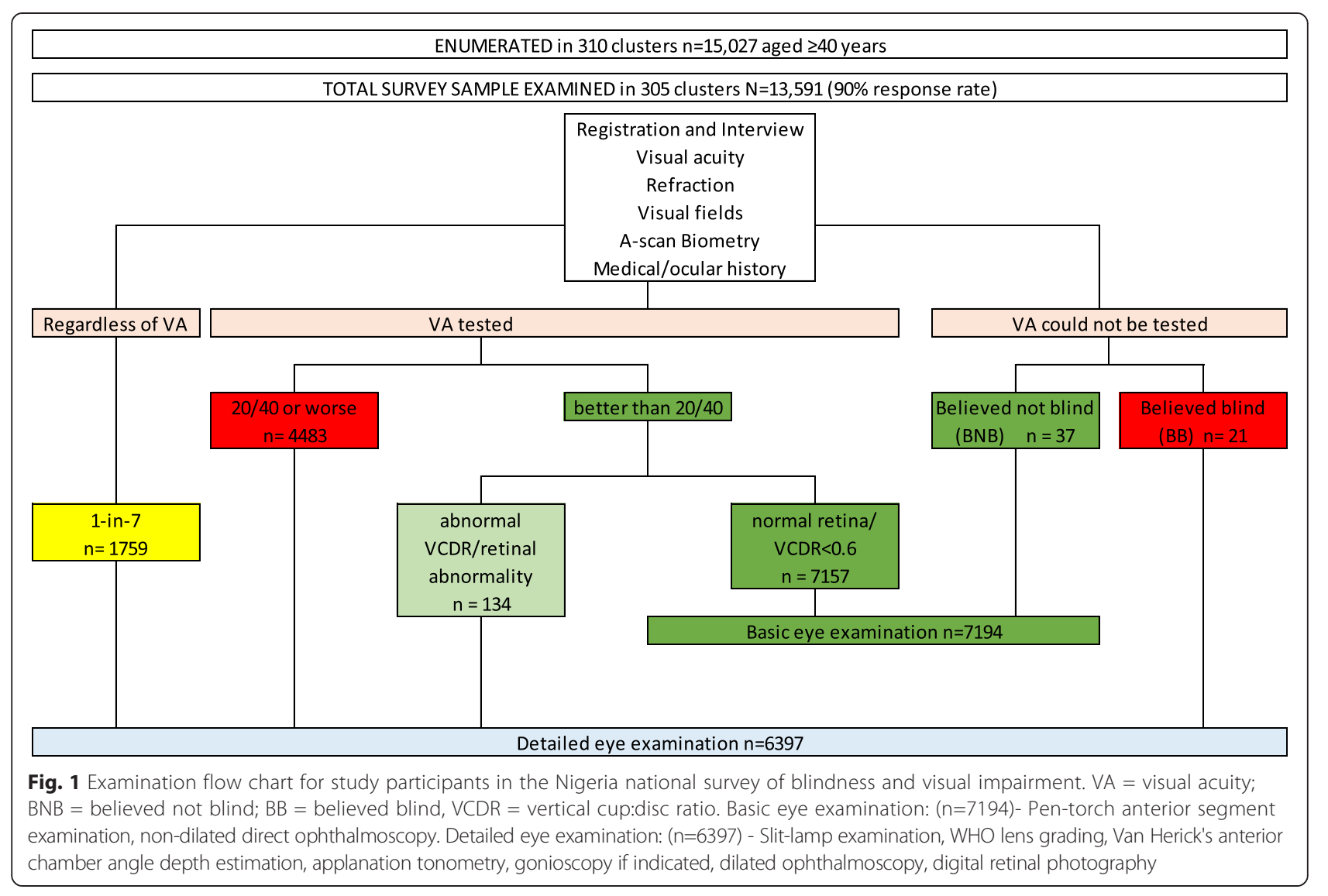

temporary examination centers set up in the community. FDT utilizes a vertical sine wave grating of low spatial frequency $(0.25 \mathrm{c} / \mathrm{deg})$ with counterphase flickering at a high temporal frequency $(25 \mathrm{~Hz})$ [28]. All participants were screened using the suprathreshold (C20-5 or C20-1) screening mode after explaining the test and running a demonstration. Each eye was tested separately without correction. The reliability indices considered were fixation error and false positive. The screening test was stopped and restarted or repeated if considered unreliable i.e., there were two or three false positives and/or two or more fixation errors. Clinically abnormal tests were not repeated. A threshold test was done if there were $\geq 3$ field defects at $p<1 \%$ or $\geq 2$ field defects at $p<0.5 \%$. If a participant could not be tested or could not see the FDT flickering black and white patterns, s/he was classified as having no FDT test and a reason was given e.g., cataract; or did not understand the test. Print-outs of all FDT tests were obtained immediately and data were extracted and entered into a database. Perimetry results were interpreted using a detailed specific algorithm (devised and adapted [27] by PGS and FK) to identify abnormal visual fields and to classify defects as glaucomatous or non-glaucomatous. The criteria used are outlined in Table 1 . The FDT result was interpreted by a $1^{\text {st }}$ reader $(\mathrm{PM})$ and validated by a 2nd (FK); any discrepancy was adjudicated (PGS). Screening reliability was defined as $\leq 1$ fixation error and/or $\leq 1$ false positive (i.e., $<33 \%$ failed reliability indices) and threshold reliability was defined as $\leq 2$ fixation errors, $\leq 2$ false positives (i.e., $\leq 33 \%$ errors on reliability indices). Tests were also considered unreliable if there were brow/ lid positions showing as uniformly dense artefact along the upper or lower edges of the FDT result chart. Unreliable results were not included.

Threshold test results were used to diagnose glaucoma if available, otherwise screening results were used. Grading used defects on the Pattern Deviation Probability (PDP) plot compared with the Total Deviation Probability (TDP) plot. Screening tests were considered normal if reliable without defects, or there were $\leq 2$ defects at $p<1 \%$; or $\leq 1$ defect at $p<0.5 \%$. Threshold tests were normal if there were no defects at $p<0.5 \%$ and $p<1 \%$, or $\leq 1$ defect at $p$ $<2 \%$, or $\leq 2$ non-adjacent defects at $p<0.5 \%$. Factors considered in categorizing defects as definitely, probably or possibly glaucomatous were position, depth and size, clustering (i.e., adjacent or not) and position; and repeatability (i.e., defect in same location on PDP and TDP plots). We could determine repeatability in participants that had both screening and threshold tests. Defects were not likely glaucomatous if 1 ) there was a highly shaded 
Table 1 Definition of glaucomatous visual field defects for level 1 evidence of glaucoma

\begin{tabular}{|c|c|c|c|c|c|}
\hline \multirow[t]{2}{*}{ FDT test defects } & \multicolumn{5}{|l|}{ Visual fields } \\
\hline & Normal & Definitely glaucoma & Probably glaucoma & Possibly glaucoma & Unlikely glaucoma $^{a}$ \\
\hline$P<5 \%$ & 2 or less non-adjacent & 4 & 3 & 2 adjacent & \\
\hline$P<2 \%$ & 1 & 3 & 2 & 1 & \\
\hline$P<1 \%$ & 0 & 2 & 1 non-edge & & \\
\hline$P<0.5 \%$ & 0 & 1 & 1 non-edge & & \\
\hline Comments & & $\begin{array}{l}\text { At any location in any } \\
\text { hemi-field }\end{array}$ & At one hemi-field & At one hemi-field & $\begin{array}{l}\text { If TDP plot is better than } \\
\text { PDP plot }\end{array}$ \\
\hline Participants with glaucoma & Total & & & & \\
\hline Number of participants ${ }^{b}$ & $268(100 \%)$ & 252 (94 \%) & $6(2.2 \%)$ & $9(3.4 \%)$ & $1(0.4 \%)$ \\
\hline Number of eyes & 310 (100\%) & 283 (91.3 \%) & 9 (2.9\%) & 13 (4.2\%) & $5(1.6 \%)$ \\
\hline
\end{tabular}

TDP total deviation probability, PDP pattern deviation probability

${ }^{a}$ Other evidence of glaucoma noted in those classified as glaucoma

${ }^{\mathrm{b}}$ In participants with bilateral glaucoma, the eye with the highest level of evidence is used to classify that person

TDP with normal PDP plot - this diffuse loss could be due to cataract, for example; 2) TDP was normal or better than the PDP plot or 3) there were vertical meridian defects. However, for diffuse defects, other compelling evidence for glaucoma classification were used (see later).

\section{Van Herick's anterior chamber angle estimation and gonioscopy}

The VH AC angle estimation was performed at the slitlamp. The relationship between the corneal slit image and AC depth was graded 0 to 4 [26]. Grades 0,1 and 2 were grouped as angle closure or likely to close angles; and grades 3 and 4 as open angles. The iridocorneal angle was assessed by gonioscopy without corneal compression and graded as either open angle or closed angle. The anterior chamber angle was classified as open when Schwalbe's line could be seen; and as closed when it could not be seen. In eyes with glaucoma, the correlation between $\mathrm{VH}$ grades and gonioscopy was assessed with the kappa statistic.

\section{IOP measurement}

Intraocular pressures were measured by Goldmann applanation tonometry using standard methods and recorded to the nearest $1 \mathrm{mmHg}$. Tonometers were checked for calibration daily according to the manufacturer's recommendation. Eyes with significant corneal surface pathology, phthisis or participants unable to fixate were excluded.

\section{Optic disc assessment}

Cup-disc ratios were assessed clinically by direct ophthalmoscopy for all participants during the basic examination, and after pupil dilation in those having the detailed examination using slit lamp biomicroscopy with a 60D lens. Clinical grading was used in analysis for participants that did not have photo VCDR grading. Methods for clinical VCDR grading by the ophthalmologists were standardized during training using standard sets of optic disc photographs and comparing the clinical grading with the VCDR measured on the retinal photo of the participant being observed.

Digital fundus images were graded independently by MEHRC using their standard protocol. Images were viewed "full screen" on either a 24-in. Eizo S2433W monitor or on a 24-in. widescreen Dell 2407WFP LCD monitor. The former was calibrated using a Datacolor Spyder2 calibrator and the latter was calibrated using a GretagMacbeth EyeOne Display2 calibrator. After determining image quality and clarity, the scleral rim was identified and the boundaries of the disc and cup identified using monocular clues such as vascular change in direction. Disc pallor gave few clues and was not used. The VCDR was then quantified. One successful measurement was performed per eye, along the vertical meridian, in Adobe Photoshop (version 7) using the measurement tool, resulting in a cup and a disc diameter value in proprietary units, the division of the two values producing the VCDR which was recorded to the nearest 0.05 . Primary grading was performed by the $1^{\text {st }}$ reader (FS) and inconclusive cases, e.g., tilted discs, blurred images, generalized disc pallor, were adjudicated by a $2^{\text {nd }}$ reader (TP) immediately. If a VCDR measurement could not be obtained, this was stated.

Inter-observer agreement for clinical VCDR measurement between ophthalmologists was assessed with the kappa statistic; each participant had two observations with the second examiner blinded to the result obtained by the first examiner. Inter-observer agreement for VCDR grading on photos was also assessed. The Bland-Altman method was applied to assess agreement between the two methods of measurement i.e., by biomicroscope funduscopy (clinical VCDR) and digital image analysis (image VCDR). 
Table 2 International Society of Geographical and Epidemiological Ophthalmology (ISGEO) definitions for glaucoma used in analysis (Adapted From Foster, 2002) [13]

\begin{tabular}{|c|c|c|c|c|c|c|}
\hline \multirow{3}{*}{ Level of evidence } & \multicolumn{2}{|c|}{ VCDR or VCDR asymmetry } & \multirow{3}{*}{ Visual fields } & \multirow{3}{*}{ Intraocular pressure } & \multirow{3}{*}{$\begin{array}{l}\text { Visual } \\
\text { acuity }\end{array}$} & \multirow{3}{*}{$\begin{array}{l}\text { Medical history } \\
\text { Other features }\end{array}$} \\
\hline & \multirow{2}{*}{$\begin{array}{l}\text { Image reading } \\
\text { analysis }\end{array}$} & \multirow{2}{*}{$\begin{array}{l}\text { Clinical records } \\
\text { analysis }\end{array}$} & & & & \\
\hline & & & & & & \\
\hline Category 1 & $\geq 97.5^{\text {th }}$ percentile: & $\geq 97.5^{\text {th }}$ percentile: & Typical defect & & & \\
\hline VCDR & 0.7 & 0.6 & & & & \\
\hline VCDR asymmetry & 0.1 & 0.2 & & & & \\
\hline Category 2 & $\geq 99.5^{\text {th }}$ percentile: & $\geq 99.5^{\text {th }}$ percentile: & Not available & & & \\
\hline VCDR & 0.75 & 0.7 & & & & \\
\hline VCDR asymmetry & 0.2 & 0.3 & & & & \\
\hline Category 2b & $\leq 97.5^{\text {th }}$ percentile: 0.7 & $\leq 97.5^{\text {th }}$ percentile: 0.6 & \pm Typical defect & $\geq 99.5^{\text {th }}$ percentile: $28 \mathrm{mmHg}$ & & RAPD, Corneal edema \\
\hline Category 3 & Not available & & Not available & $\geq 99.5^{\text {th }}$ percentile: $28 \mathrm{mmHg}$ & $<20 / 400$ & Surgery for glaucoma \\
\hline
\end{tabular}

$V C D R$ vertical cup:disc ratio, $R A P D$ relative afferent pupillary defect

\section{Glaucoma diagnostic algorithm}

Glaucoma was classified according to the ISGEO criteria, using percentile distributions of VCDR, VCDR asymmetry and IOP in normal Nigerians, derived from the normative dataset $(n=1759)$ of this study population [29] (Table 2). The diagnosis of glaucoma started with VCDR findings
(Fig. 2). Category 1 required structural and functional evidence i.e., $97.5^{\text {th }}$ percentile of the VCDR $(\geq 0.7)$ or VCDR asymmetry $(\geq 0.1)$ in our normal population and visual field loss typical of glaucoma. Category 2 required advanced structural damage i.e., $99.5^{\text {th }}$ percentile VCDR $(\geq 0.75)$ or VCDR asymmetry $(\geq 0.2)$ in the absence of

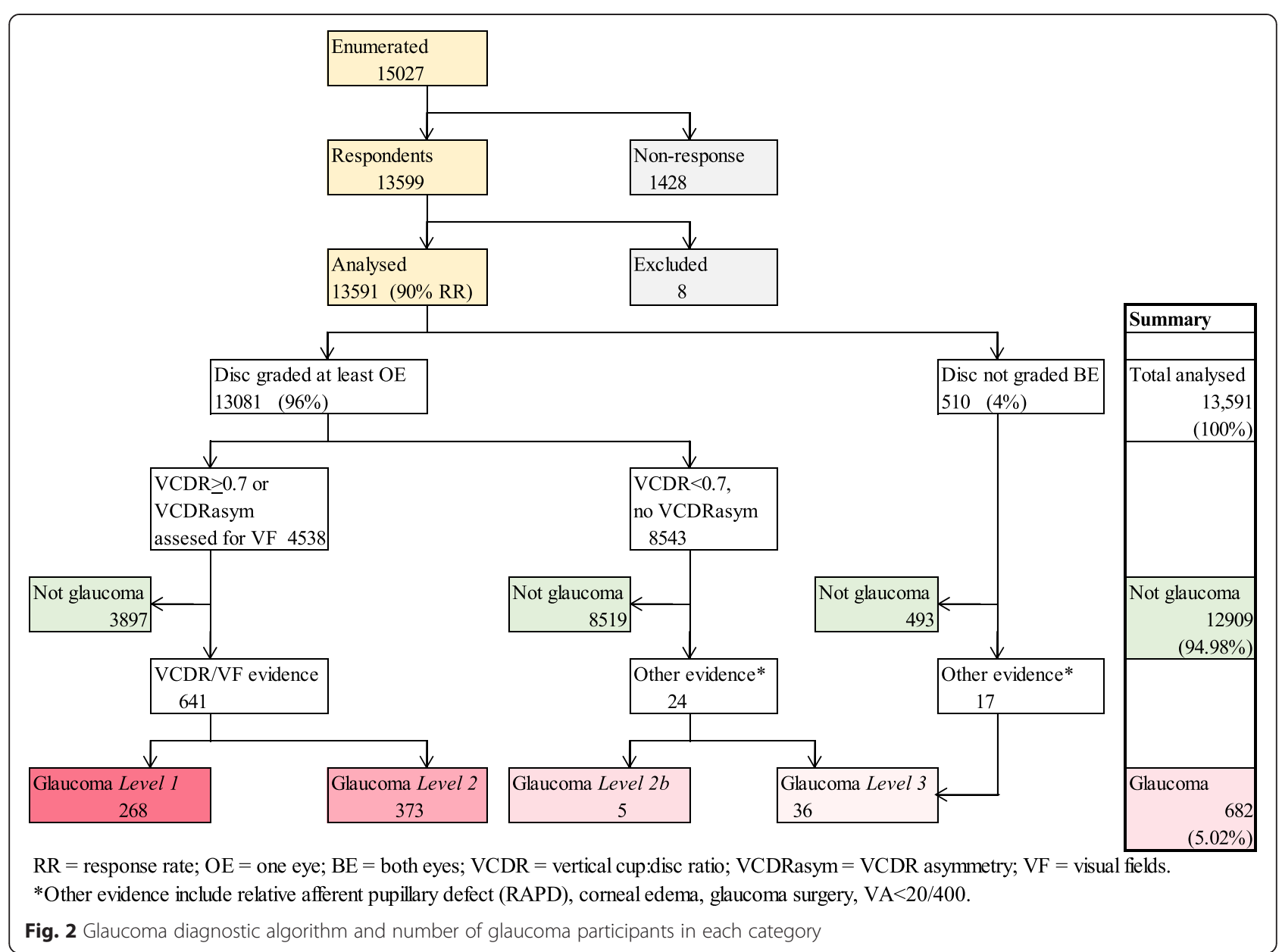


visual field evidence i.e., when a useful visual field result was not possible or available. Category 3 applied when the optic disc was not seen and visual field testing was not possible, and used: a) blindness (VA $<3 / 60$ ) with the $99.5^{\text {th }}$ percentile IOP ( $\geq 28 \mathrm{mmHg}$ ), or b) diagnosed with/being treated for glaucoma. An additional level of evidence (level $2 \mathrm{~b})$ was added where the optic disc was visualized but the VCDR was $<99.5^{\text {th }}$ percentile and visual fields were not available or if visual fields were interpreted as "unlikely glaucoma" but there were other compelling evidence such as RAPD, high IOP and/or corneal edema. Other glaucomatous optic nerve head features such as localized narrowing of the rim, optic disc hemorrhages, and retinal nerve fiber layer defects are not included in the ISGEO classification, and so individuals with these signs only (i.e., no visual field defects; IOP within the normal range for the study population) would not have been classified as having glaucoma. These cases were adjudicated by glaucoma specialists (RW and WN). A person was said to have glaucoma if there was glaucoma in one or both eyes.

\section{Type of glaucoma}

Glaucoma was classified as primary and secondary glaucoma. Primary glaucoma was classified as primary open-angle glaucoma (POAG) or primary angle-closure glaucoma (PACG) according to angle morphology viewed by gonioscopy. Glaucoma was classified as secondary where there was an underlying cause such as AC angle neovascularization, exfoliation, pigment dispersion, trauma, surgical procedure, couching or uveitis. The type was unclassified in eyes that did not have gonioscopy.

\section{Data analysis and statistical methods}

Visual acuities were categorized using the WHO classification of blindness and visual impairment with addition of a category for mild visual impairment (worse than 6/ 12 but up to 6/18). The classification uses presenting VA in the better seeing eye. Age was categorized in 10-year groups. Any ability to read and write was classified as literate. Ethnic groups represented by $\geq 200$ participants were analyzed separately (i.e., Hausa, Yoruba, Igbo, Fulani, Kanuri, Nupe, Ijaw, Ibibio, Tiv and Urhobo). Ethnic groups with $<200$ participants were grouped as "Others" and analyzed collectively. Settlements with a population of $\leq 20,000$ were classified as rural.

The percentile VCDR values used for classification of glaucoma in this study were derived from the photo VCDR grades of the 'normative' data. The percentile values for the distribution of the clinical VCDR records are included in Table 2 for comparison.

Statistical analysis was performed using Stata (Stata/IC 13.0; Stata Corp, College Station, TX). A descriptive analysis of the study population was undertaken. Univariate analysis was performed to describe socio-demographic characteristics (age, gender, ethnic group, literacy and rural/urban place of residence). The age/sex-specific prevalence of glaucoma with $95 \%$ confidence intervals (CI) was calculated taking account of additional variation introduced by the stratified cluster sampling design. Missing values were indicated and excluded in the analysis.

\section{Results}

A total of 15,027 adults aged $\geq 40$ years were enumerated in 310 clusters, 13,591 (90\%) of whom were examined in 305 clusters. 6,397 participants had detailed eye examination, 3814 (59.6 \%) of whom had images for VCDR assessment in both eyes and 817 (12.8\%) in one eye. Where there was no disc image (2624 eyes of 1329 [20.8 \%] participants), clinical VCDR grade was used (Table 3). Reasons why there were no disc images are stated in Table 4. Photos were ungradable if no optic disc features could be assessed due to blur or wrong field definition. Clinical VCDR grades were also used in participants undergoing the basic eye examination only. In the whole study sample, a total of 25,289 (93 \%) eyes of 13,081 (96\%) participants had photographic or clinical VCDR grades; $510(4 \%)$ participants did not have VCDR graded in both eyes (Fig. 2).

Table 3 Summary of completeness of data for participants undergoing full examination $(N=6397)$

\begin{tabular}{|c|c|c|c|c|c|c|c|c|c|c|}
\hline & \multicolumn{6}{|c|}{ Eye level data } & \multicolumn{4}{|c|}{ Person level data } \\
\hline & \multicolumn{2}{|c|}{ Right eye } & \multicolumn{2}{|c|}{ Left eye } & \multicolumn{2}{|c|}{ All eyes } & \multicolumn{2}{|c|}{ One/both eyes } & \multicolumn{2}{|c|}{ Both eyes } \\
\hline & $N$ & $\%$ & $N$ & $\%$ & $N$ & $\%$ & $N$ & $\%$ & $N$ & $\%$ \\
\hline Total & 6397 & & 6397 & & 12,794 & & 6397 & & 6397 & \\
\hline \multicolumn{11}{|l|}{ Examination } \\
\hline Van Herick's & 5830 & 91.1 & 5821 & 91.0 & 11,651 & 91.1 & 5967 & 93.3 & 5684 & 88.9 \\
\hline Intra-ocular pressure & 5496 & 85.9 & 5478 & 85.6 & 10,974 & 85.8 & 5638 & 88.1 & 5336 & 83.4 \\
\hline \multicolumn{11}{|l|}{ Disc grading } \\
\hline Photo & 4203 & 65.7 & 4242 & 66.3 & 8445 & 66.0 & 4631 & 72.4 & 3814 & 59.6 \\
\hline Clinical & 1320 & 20.6 & 1304 & 20.4 & 2624 & 20.5 & 1329 & 20.8 & 993 & 15.5 \\
\hline None & 874 & 13.7 & 851 & 13.3 & 1725 & 13.5 & - & - & 437 & 6.8 \\
\hline
\end{tabular}


Table 4 Reasons why there was no photo disc grading in 4349 (34 \%) eyes among those who had full examination $(n=12,794$ eyes $)$

\begin{tabular}{lllll}
\hline Reason & Right eye & Left eye & All eyes & $\%$ \\
\hline Eye disease & & & & \\
Cataract & 552 & 469 & 1021 & $24 \%$ \\
Corneal opacity & 304 & 295 & 599 & $14 \%$ \\
Other ocular pathology & 166 & 192 & 358 & $8 \%$ \\
Participants factors & & & 1978 & $46 \%$ \\
Uncooperative & 27 & 31 & 58 & $1 \%$ \\
Other e.g., home visit & 31 & 27 & 58 & $1 \%$ \\
Technical reasons & & & 116 & $2 \%$ \\
Faulty camera & 471 & 472 & 943 & $22 \%$ \\
No electricity & 144 & 144 & 288 & $7 \%$ \\
& & & 1231 & $28 \%$ \\
Other & & & & \\
No reason stated & 271 & 312 & 583 & $14 \%$ \\
Ungradable photos & & & & \\
Total & 228 & 213 & 441 & $10 \%$ \\
\hline
\end{tabular}

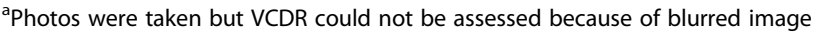
due to media opacity or poor positioning of the participant

The kappa for inter-observer agreement on ophthalmologists' clinical measurement of VCDR within 0.1 was $\kappa=0.86$ (almost perfect agreement) and classifying $\geq 0.6$ or $<0.6$ was $\kappa=0.47$ (moderate agreement). Overall, the inter-observer agreement between graders for the image VCDR grading at MEHRC was $99.7 \%$. The Bland-Altman limits of agreement between the clinical and the image VCDR measurements for $95 \%$ of eyes were lower limit of -0.2 to upper limit of 0.3 ; and $93 \%$ eyes had a difference of $\leq 0.25$ between the two methods of VCDR measurement. In participants undergoing detailed eye examination ( $n=6397), 93 \%$ and $88 \%$ had VH AC depth estimation and IOP measurement in at least one eye, respectively (Table 3). With 94\% agreement, the kappa for correlation of gonioscopy (closed/open) Vs VH AC (grades 0-2/3-4) in 397 eyes with glaucoma was $\kappa=0.70$ (substantial agreement).

As shown in Fig. 2, 770 participants had VCDR $\geq 0.7$ in one or both eyes and a further 3768 had VCDR asymmetry $\geq 0.1$, thus a total of 4995 eyes in 4538 participants required visual field analysis (for level 1 evidence) which were available for 3016 (60.4\%) eyes of 2725 (60.1\%) persons. Glaucoma was diagnosed in $63 \%$ (485/770) participants with VCDR $\geq 0.7 / 0.75$, and in $4.1 \%(156 / 3768)$ participants with VCDR asymmetry. Other participants were assessed for level $2 \mathrm{~b}$ and level 3 evidence. The
Table 5 Classification of participants with glaucoma by levels of evidence (as described in Table 2)

\begin{tabular}{lll}
\hline & \multicolumn{2}{l}{ Participants with glaucoma } \\
\cline { 2 - 3 } Level of evidence & Number of participants & Number of eyes \\
\hline Category 1 & $155(22.7 \%)$ & $197(20.8 \%)$ \\
VCDR & $113(16.6 \%)$ & $113(11.9 \%)$ \\
VCDR asymmetry & $268(39.3 \%)$ & $310(32.7 \%)$ \\
Total & & \\
Category 2 & $330(48.4 \%)$ & $511(53.8 \%)$ \\
VCDR & $43(6.3 \%)$ & $43(4.5 \%)$ \\
VCDR asymmetry & $373(54.7 \%)$ & $554(58.3 \%)$ \\
Total & $5(0.7 \%)$ & $10(1.0 \%)$ \\
Category 2b & $36(5.3 \%)$ & $76(8.0 \%)$ \\
Category 3 & $682(100 \%)$ & $950(100.0 \%)$ \\
Total glaucoma &
\end{tabular}

diagnosis of glaucoma was made in a total of 950 eyes of 682 participants - by photo VCDR in 352 (51.6\%), clinical VCDR in 294 (43.1\%) and the disc was not seen in 36 (5.3\%). Thus, glaucoma diagnosis was made by level 1 evidence in 268 (39.3\%), level 2 evidence in $373(54.7 \%)$, level $2 \mathrm{~b}$ in $5(0.7 \%)$ and level 3 in 36 $(5.3 \%)$ participants (Table 5).

\section{Prevalence and types of glaucoma}

The prevalence of glaucoma of all types was 5.02\% (95\% CI $4.60-5.47 \%)$. The prevalence increased with increasing age and was higher in males, those who were not literate and the Igbo ethnic group (Table 6). These differences were statistically significant. The age-specific prevalence and the magnitude of glaucoma in Nigeria derived by direct standardization with the 2012 Nigeria population are shown in Table 7. There are estimated to be 1.2 million Nigerians aged $\geq 40$ years with glaucoma.

Among the 243 participants with primary glaucoma classified according to pathophysiology based on AC angle morphology by gonioscopy, 208 (86 \%) were classified as POAG and 35 (14 \%) as PACG (Table 8). PACG was more common in women but the difference was not statistically significant $(p=0.08)$. There were no differences in age, ethnic distribution or rural/urban place of residence between the two groups. Additionally, there was no statistically significant difference in awareness of having glaucoma $(p=0.55)$ : 1 in 8 of those with POAG and 1 in 12 of those with PACG knew they had the disease. IOPs were higher in PACG than POAG: the mean IOP was $34 \mathrm{mmHg}$, standard deviation (SD) 13 in PACG and $27 \mathrm{mmHg}$, SD 11 in POAG $(p<0.001)$. 
Table 6 Socio-demographic characteristics of participants with glaucoma in the study population

\begin{tabular}{|c|c|c|c|c|c|}
\hline & & \multirow{2}{*}{$\begin{array}{l}\text { Total } \\
\mathrm{N}\end{array}$} & \multicolumn{3}{|c|}{ Participants with glaucoma } \\
\hline & & & $N$ & $\%$ & $95 \% \mathrm{Cl}$ \\
\hline Total & & $13,591(100 \%)$ & 682 & 5.02 & $4.60-5.47$ \\
\hline \multicolumn{6}{|c|}{ Socio-demographic factors } \\
\hline \multirow[t]{6}{*}{ Age group (years) } & $40-49$ & 4889 & 93 & 1.90 & $1.55-2.33$ \\
\hline & $50-59$ & 3577 & 130 & 3.63 & $3.03-4.36$ \\
\hline & $60-69$ & 2773 & 178 & 6.42 & $5.50-7.48$ \\
\hline & $70-79$ & 1653 & 178 & 10.77 & $9.24-12.52$ \\
\hline & $80+$ & 699 & 103 & 14.74 & $12.31-17.54$ \\
\hline & & & & & $p<0.001$ \\
\hline \multirow[t]{3}{*}{ Gender } & Female & 7345 & 328 & 4.47 & $3.98-5.00$ \\
\hline & Male & 6246 & 354 & 5.67 & $5.05-5.47$ \\
\hline & & & & & $p=0.002$ \\
\hline \multirow[t]{12}{*}{ Ethnic group ${ }^{a}$} & Hausa & 3375 & 130 & 3.85 & $3.00-4.93$ \\
\hline & Yoruba & 2669 & 156 & 5.84 & $4.94-6.90$ \\
\hline & Igbo & 1918 & 149 & 7.77 & $6.57-9.16$ \\
\hline & Fulani & 840 & 30 & 3.57 & $2.53-5.01$ \\
\hline & Kanuri & 353 & 18 & 5.10 & $3.40-7.58$ \\
\hline & Tiv & 342 & 11 & 3.22 & $2.29-4.51$ \\
\hline & ljaw & 251 & 15 & 5.98 & $4.46-7.96$ \\
\hline & Urhobo & 245 & 7 & 2.86 & $1.50-5.37$ \\
\hline & Ibibio & 212 & 12 & 5.66 & $2.35-13.03$ \\
\hline & Nupe & 211 & 11 & 5.21 & $3.41-7.88$ \\
\hline & Others & 3117 & 139 & 4.46 & $3.72-5.33$ \\
\hline & & & & & $p<0.001$ \\
\hline \multirow[t]{3}{*}{ Literacy } & Literate & 5925 & 248 & 4.19 & $3.60-4.86$ \\
\hline & Illiterate & 7666 & 434 & 5.66 & $5.14-6.23$ \\
\hline & & & & & $p=0.001$ \\
\hline \multirow[t]{3}{*}{ Place of residence } & Rural & 10,540 & 520 & 4.93 & $4.46-5.46$ \\
\hline & Urban & 3051 & 162 & 5.31 & $4.47-6.30$ \\
\hline & & & & & $p=0.473$ \\
\hline \multirow[t]{3}{*}{ Visual status } & Not blind & 13,022 & 546 & 4.19 & $3.83-4.59$ \\
\hline & Blind & 569 & 136 & 23.90 & $20.24-27.99$ \\
\hline & & & & & $p<0.001$ \\
\hline
\end{tabular}

\section{Other findings}

Only $5.6 \%(38 / 682)$ of all participants with glaucoma knew they had the condition. The commonest causes of secondary glaucoma ( $n=53$ participants) were couching (an ancient, traditional non-medical manipulation of the crystalline lens; $38 \%)$, trauma (21\%), uveitis (19\%) and following intracapsular cataract surgery (17\%). Over a third of the eyes with glaucoma (365; $38 \%$ ) had a presenting VA worse than 3/60; and 1 in every 5 persons with glaucoma (136; $20 \%$ ) was blind (VA worse than 3/60 in the better eye). In $68 \%$ of the 136 blind with glaucoma, the main cause of blindness was attributable to glaucoma. Among the 40-49 year-group with glaucoma, $13 \%$ were blind, and this age-specific proportion of blindness among glaucoma participants increased with age to $30 \%$ in the $80+$ years age-group.

Figure 3 shows the distribution of IOP in all eyes: the mean IOP was $14 \mathrm{mmHg}$, SD 4 in the non-glaucomatous eyes compared to $23 \mathrm{mmHg}$, SD 12 in the glaucoma eyes. The difference in the mean values was statistically significant $(p<0.001)$. The modal IOP was $12 \mathrm{mmHg}$ in both groups. There were three different peaks at 12,28 and 
Table 7 Age-standardized glaucoma prevalence rates

\begin{tabular}{|c|c|c|c|c|c|c|c|}
\hline & \multirow{2}{*}{\multicolumn{2}{|c|}{ Study sample }} & \multicolumn{4}{|c|}{ Prevalence of glaucoma } & \multirow{3}{*}{$\begin{array}{l}\text { Magnitude of glaucoma } \\
\text { Estimated numbers }\end{array}$} \\
\hline & & & \multicolumn{2}{|c|}{ Crude rate } & \multicolumn{2}{|c|}{ Age-adjusted rate $^{a}$} & \\
\hline & $N$ & $\%$ & $N$ & $\%$ & $\%$ & $95 \% \mathrm{Cl}$ & \\
\hline \multicolumn{8}{|c|}{ Age group (years) } \\
\hline $40-49$ & 4889 & 35.97 & 93 & 1.90 & 1.51 & $1.96-2.94$ & 166,308 \\
\hline $50-59$ & 3577 & 26.32 & 130 & 3.63 & 3.69 & $2.98-4.29$ & 232,792 \\
\hline $60-69$ & 2773 & 20.40 & 178 & 6.42 & 8.85 & $3.99-5.43$ & 318,689 \\
\hline 70-79 & 1653 & 12.16 & 178 & 10.77 & 16.85 & $5.91-8.00$ & 321,820 \\
\hline $80+$ & 699 & 5.14 & 103 & 14.74 & 12.32 & $14.72-20.98$ & 181,807 \\
\hline Total & 13,591 & 100 & 682 & 5.02 & 5.02 & $4.60-5.47$ & $1,221,416$ \\
\hline
\end{tabular}

Cl confidence interval

${ }^{\text {a }}$ Standardized with the 2012 Nigeria population

$50 \mathrm{mmHg}$ in the IOP distribution of the eyes with glaucoma. About half (56\%) of the eyes with glaucoma had IOP $\leq 22 \mathrm{mmHg}$. Conversely, $4 \%$ had IOP $>21 \mathrm{mmHg}$ but did not have glaucoma.

\section{Discussion}

The Nigeria Blindness Survey was the largest, national population-based survey of eye disease in an ethnically diverse, indigenous black African population, giving precise estimates of the prevalence of glaucoma. The sample was nationally representative by age, gender, ethnicity, rural/ urban residence and socioeconomic status [24], with a high response rate and the results are generalizable to the whole country and also to people of the West African diaspora around the world whose predecessors were victims of the slave trade e.g., African Caribbean and African American people. Though now genetically mixed to varying extent, our study population is likely to have the same genetic determinants of the glaucoma seen in those populations. Additional strengths are the standardized protocol, the same clinicians and equipment were used throughout the study, and photographic VCDR grading was performed by the MEHRC, an independent, internationally recognized reading center. Furthermore, the centile values for VCDR and IOP distribution in the population used to define glaucoma were derived from the same study population.

Table 8 Proportion of the different types of glaucoma in the Nigeria National Survey of Blindness and Visual Impairment

\begin{tabular}{lll}
\hline \multirow{2}{*}{ Glaucoma type } & \multicolumn{2}{l}{ Proportion of glaucoma } \\
\cline { 2 - 3 } \cline { 2 - 2 } All glaucoma $^{a}$ & $\mathrm{~N}$ & $\%$ \\
POAG & 682 & 100.0 \\
PACG & 208 & 30.5 \\
Secondary glaucoma & 35 & 5.1 \\
Unclassified & 53 & 7.8 \\
\hline
\end{tabular}

POAG primary open angle glaucoma, PACG primary angle-closure glaucoma

${ }^{\mathrm{a}}$ All glaucoma prevalence is $5.02 \%$ (95\% Cl 4.60-5.47\%)

${ }^{\mathrm{b}} \mathrm{No}$ data on gonioscopy, thus not classified by anterior chamber angle morphology
The survey indicates that 1.1 to 1.4 million adults in Nigeria have glaucoma, most of whom are not aware that they have the disease. One in every 20 Nigerians aged 40 years and above has glaucoma, and one in five being blind. There are approximately 8500 people aged 40 years and above with glaucoma per million population. The high prevalence and high rate of blindness confirm glaucoma to be of public health importance and should become a priority among healthcare planners and policy makers, emphasizing the need for glaucoma care pathways for early detection and treatment to prevent blindness. In Nigeria, $8 \%$ of glaucoma was secondary, with over half of these following procedures for cataract, particularly couching, which is still widely practiced in Nigeria despite very poor visual outcomes [30]. This underscores the need for high quality, affordable and accessible cataract surgical services. The findings have public health implications for other countries in sub-Saharan Africa which share similar socio-demographic characteristics.

The prevalence of glaucoma in Nigeria is similar to that in Temba, South Africa [20], slightly higher than in South African Zulus [19] and in Kongwa, Tanzania [18] but lower than in Tema, Ghana [21] and Akinyele, SW Nigeria [22]. Although these surveys were undertaken in localized populations, there seems to be an emerging pattern with the prevalence being higher in West Africa than in South Africa which in turn is higher than in East Africa. The Ghana study [21] had a high proportion of Level 1 diagnosis $(87.2 \%)$ compared with our study (39.3\%) as in Nigeria there were high rates of cataract and other pathology which precluded visual field assessment. As Level 2 requires evidence of more advanced structural damage our estimates for Nigeria are, therefore, minimum estimates.

The prevalence of glaucoma in Nigeria is lower than that of POAG reported from Barbados (6.7 \%, 95 \% CI 6.3-7.8) [17], being similar to black populations in the United States of America (USA) [15] but slightly higher than in Asian populations [31-38] and much higher than white populations in the USA [15, 39], Australia [40] and Europe 


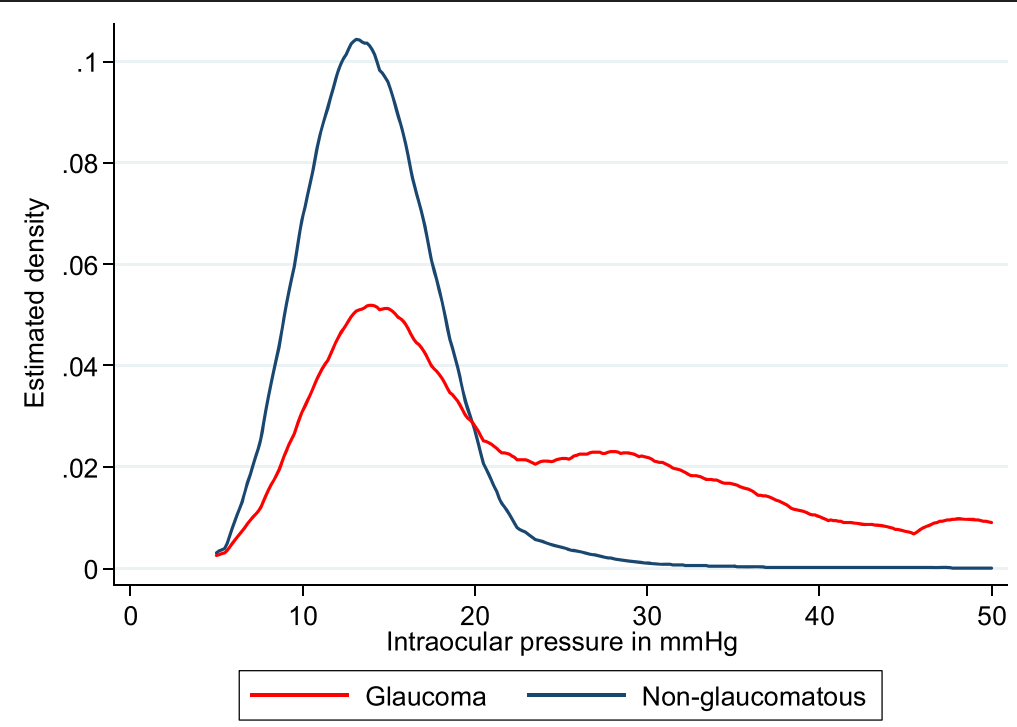

Fig. 3 Distribution of IOP in glaucoma and non-glaucomatous eyes

[41-44]. The prevalence of glaucoma in Nigeria is also higher than in Brazil [45], Iran [46], indigenous populations in Australia [47] and Qatar [48]. Regional/racial variations in prevalence have been attributed to genetic and possible environmental differences $[49,50]$. Susceptibility gene loci significantly associated with POAG and genes involved in IOP regulation have been studied in some African populations $[51,52]$. In Nigeria, the Igbo, a rather homogenous ethnic group, had the highest prevalence of glaucoma which may also reflect genetic susceptibility.

The relatively high age-specific prevalence of glaucoma in 40-49 year olds in Nigeria and the high proportion of glaucoma blindness suggest severity at an earlier age $[15,17,21,22]$ and more aggressive course [53] in Blacks than in Caucasians [41, 42, 44] and some Asian populations [33,34] over and above lack of diagnosis and treatment since the high proportions of undiagnosed glaucoma are relatively similar (Table 9). However, this could also be the natural history signifying poor access to treatment. Additionally, because of the earlier age of onset and longer years with untreated glaucoma, the risk of going blind would be much greater. The racial/regional disparity in disease severity may be attributed to additional factors such as inflammation $[54,55]$ and the different peaks of IOP in eyes with glaucoma may indicate genetic susceptibility at varying levels of IOP. However, these interpretations are speculative and warrant further research.

The classification of glaucoma by pathophysiological mechanism based on angle morphology is important because POAG and PACG have different natural histories and different management strategies. In Nigeria POAG was the commonest type of glaucoma, as reported in other black populations [3, 15-22, 45].
It is acknowledged that communities in Nigeria, where prior diagnosis of glaucoma is low, have extremely little knowledge about glaucoma. Questions were, therefore, not asked on whether first-degree relatives had glaucoma as participants would be highly unlikely to know. In addition, the ISGEO classification does not take firstdegree relatives into account.

It is noteworthy that at least half of the glaucoma eyes had an IOP less than the mean +2SD IOP $(22 \mathrm{mmHg})$ of non-glaucoma participants. The important implication is that IOP is unable to differentiate between those with glaucoma and those without glaucoma.

A limitation of this study is that the 'gold standard' Humphrey field analyzer was not used as, unlike the portable FDT perimeter, it would not have been feasible to transport it to all examination centers especially in the terrain and environment of the survey. Nevertheless, we had an acceptable and reproducible test of visual function based on the central $20^{\circ}$ field of vision. Another limitation was that pachymetry was not done. The data would have added more information on corneal thickness in relation to glaucoma. Interestingly, in the Barbados Eye Studies, corneal thickness tended to be thinner in the black participants than in the white participants but was not correlated to IOP [56]. However, as corneal thickness decreased, there was a higher likelihood of incident OAG [57]. Also, not all participants had dilated disc assessment or photographic disc grading as this was not possible given the large sample size of the study. The fundus camera produced non-stereoscopic images and monocular clues were used to determine optic disc and cup boundaries. Though this may have led to misclassification, most of the cases classified as glaucoma in this survey were "barn-door". Even though there is a tendency for non-stereoscopic 
Table 9 Prevalence of Glaucoma in some population-based studies for age $\geq 40$ years

\begin{tabular}{|c|c|c|c|c|c|c|c|}
\hline \multirow[t]{2}{*}{ Study population } & \multirow{2}{*}{$\begin{array}{l}\text { Examined } \\
\text { (response rate \%) }\end{array}$} & \multicolumn{3}{|c|}{ Prevalence of glaucoma } & \multirow{2}{*}{$\begin{array}{l}\text { Undiagnosed } \\
\text { glaucoma (\%) }\end{array}$} & \multirow{2}{*}{$\begin{array}{l}\text { Proportion } \\
\text { blind (\%) }\end{array}$} & \multirow[t]{2}{*}{ Reference } \\
\hline & & $n$ & $\begin{array}{l}\text { All glaucoma \% } \\
(95 \% \text { Cl) }\end{array}$ & 40-49 years age-specific & & & \\
\hline Nigeria, National & $13,951(90)$ & 682 & $5.0(4.6-5.5)$ & $1.9(1.6-2.3)$ & 94 & 20 & This study \\
\hline \multicolumn{8}{|l|}{ Africa } \\
\hline Kongwa, Tanzania & $3247(89)$ & 135 & $4.2(3.5-4.9)$ & $1.7(1.1-2.5)$ & 98 & 14 & [18] \\
\hline Hlabisa, South Africa & $1005(90)$ & 41 & $4.5(3.2-6.1)$ & $1.2(0.2-3.4)$ & 90 & & [19] \\
\hline Temba, South Africa & $839(75)$ & 55 & $5.3(3.9-7.1)$ & $1.1^{\mathrm{b}}$ & 87 & & [20] \\
\hline Tema, Ghana & $5603(82)$ & 32 & $6.5(5.8-7.1)$ & $3.2(2.7-4.1)$ & 97 & 3 & [21] \\
\hline Akinyele, Nigeria & $811(90)$ & 59 & $7.3(5.5-9.1)$ & $4.6(2.1-7.1)$ & 90 & 6 & {$[22]$} \\
\hline \multicolumn{8}{|l|}{ Asia } \\
\hline Qatar & $3149(97)$ & 67 & $1.7(1.7-1.8)$ & $1.45^{b}$ & 51 & 6 & {$[48]$} \\
\hline Yazd, Iran & $1990(86)$ & 87 & $4.4(3.3-5.4)$ & $1.6(0.8-2.4)$ & 90 & & {$[46]$} \\
\hline Chinese, Singapore & $1232(72)$ & 45 & $3.2(2.3-4.1)^{\mathrm{a}}$ & $1.1(0.2-4.8)$ & 62 & & [31] \\
\hline Chinese, Singapore & $3353(73)$ & 134 & $3.2(2.7-3.9)^{\mathrm{a}}$ & $0.7^{b}$ & 85 & 10 & [38] \\
\hline Malay, Singapore & $3280(79)$ & 150 & $3.4(3.3-3.5)^{a}$ & $2.2^{b}$ & 92 & 10 & {$[36]$} \\
\hline Indian, Singapore & $3400(76)$ & 78 & $1.9(1.5-2.5)^{a}$ & $1.3^{b}$ & 72 & 10 & [35] \\
\hline Beijing, China & $4439(83)$ & 158 & $3.7(3.1-4.2)$ & $2.2(1.5-3.0)$ & - & 2 & {$[37]$} \\
\hline Kailu, China & $5197(87)$ & 169 & $2.9(2.0-3.8)^{a}$ & $2.0(1.3-2.7)$ & 66 & 7 & {$[32]$} \\
\hline Bhaktapur, Nepal & 3991 (83) & 75 & $1.8(1.7-1.9)^{a}$ & $0.3^{b}$ & 96 & 2 & {$[33]$} \\
\hline Central India & $4711(80)$ & 122 & $3.5(2.8-4.1)$ & $1.0(0.5-1.6)$ & - & 1 & [34] \\
\hline \multicolumn{8}{|l|}{ Australia } \\
\hline Indigenous, Australia & $1061(64)$ & 26 & $2.2(1.6-3.6)$ & $1.5(0.4-2.5)$ & 81 & 12 & [47] \\
\hline \multicolumn{8}{|l|}{ Europe } \\
\hline Ponza, Italy & $1034(84)$ & 39 & $3.8^{b}$ & $0(0.0-1.7)$ & - & & {$[42]$} \\
\hline Egna-Neumarkt, Italy & $4297(74)$ & 121 & $2.9^{b}$ approx & $0.5^{b}$ & - & & [41] \\
\hline Wroclaw, Poland & $4853(83)$ & 79 & $1.6(1.3-2.0)$ & $0.4(0.1-1.1)$ & 71 & & [44] \\
\hline
\end{tabular}

Cl confidence interval

${ }^{\text {a Adjusted rates }}$

${ }^{\mathrm{b}} 95 \%$ confidence interval not reported

- no data

assessments to yield slightly varied optic disc parameters $[58,59]$, these differences were inconsistent and the agreement between stereoscopic and non-stereoscopic VCDR assessment were generally extremely good and repeatable [58]. A further limitation was that the fundus camera was not calibrated for disc size so VCDRs could not be adjusted for disc size. Technical difficulties in the field (faulty camera or generator) meant that disc images were not obtained in 616 participants when needed. High humidity damaged the mirror coating of gonioscopy lenses so that some eligible participants did not have gonioscopy performed and VH AC angle estimation was used instead. Hence, the proportions for angle-closure glaucoma and open-angle glaucoma were obtained only from participants that had gonioscopy. Additionally, lack of indentation gonioscopy, use of a one-mirror gonioscopy lens, and defining open-angle glaucoma as a visible Schwalbe's line may have led to some misclassification of the type of glaucoma. The survey protocol indicated detailed eye examination of those with VCDR asymmetry of $\geq 0.2$ whereas the asymmetry required for Level 1 diagnosis in later analysis was found to be 0.1 . In individuals with VCDR asymmetry between 0.1 and 0.2 , the diagnosis of glaucoma was based on the presence of glaucomatous visual fields. The ISGEO classification system is designed to identify moderate, severe glaucoma and those blind from glaucoma and therefore glaucoma 'suspects' and those with early disease may not have been captured. Our estimate is, therefore, a minimal estimate.

One survey team inadvertently used the C-20-1 FDT screening mode in 141 clusters. The C-20-1 mode has greater specificity and is less likely to misclassify a normal field. The C-20-5 has higher sensitivity at detecting early defects at the expense of lower specificity. To overcome 
the difference visual fields were classified according to the probability of pattern deviation and were equalized for the 2 screening modes.

Having described the high prevalence and distribution of glaucoma in this comprehensive and representative study, we are obliged to recommend a strategy for the prevention blindness and visual impairment from glaucoma in Nigeria and more widely in West Africa. The clinical care of glaucoma in Nigeria remains challenging and we suggest a top-down approach [60].

\section{Conclusion}

This nationally representative survey in Nigeria indicates a high prevalence of glaucoma, with ethnic variation, severity at an earlier age and high rates of blindness. The latter is likely to reflect an aggressive natural history as well as lack of awareness of the condition and low levels of treatment. Most glaucoma in Nigeria is POAG with a high proportion of secondary glaucoma being the consequence of procedures for cataract. The findings shed light on the more severe and prevalent disease seen in black communities of the West African diaspora around the world and quantify the enormous challenge of preventing blindness from glaucoma in West Africa and in people of this ethnic origin. Public health control strategies with high quality integrated glaucoma care services will be required to reduce morbidity and blindness.

\begin{abstract}
Abbreviations
AC: anterior chamber; BIO: binocular indirect ophthalmoscopy; Cl: confidence interval; FDT: frequency doubling technology; GPZ: geo-political zone; IOP: intraocular pressure; ISGEO: International Society of Geographical and Epidemiological Ophthalmology; MEHRC: Moorfields Eye Hospital Reading Centre; NC: North central; NE: North east; NW: North west; OAG: open-angle glaucoma; PACG: primary angle-closure glaucoma; PDP: pattern deviation plot; POAG: primary open-angle glaucoma; RAPD: relative afferent pupillary defect; SD: standard deviation; SE: South east; SS: South south; SW: South west; TDP: total deviation plot; VA: visual acuity; VCDR: vertical cup:disc ratio; VH: Van Herick's; WHO: World Health Organization.
\end{abstract}

\section{Competing interests}

No conflicting relationship exists for any author.

\section{Authors' contributions}

FK developed the study concept and design, carried out acquisition of data performed the statistical analysis and interpretation of data, drafted the manuscript, obtained funding and is accountable for all aspects of the work. GE carried out acquisition and interpretation of data and revised the manuscript for important intellectual content. MR participated in acquisition and interpretation of data and revised the manuscript for important intellectual content. PS involved in developing the study design, participated in interpretation of data, revised the manuscript for important intellectual content and was involved in the study supervision. RW was involved in developing the study design, participated in the interpretation of data, helped in drafting the manuscript, revised the manuscript for important intellectual content and was involved in the study supervision and coordination. WN was involved in developing the study design, participated in the interpretation of data, revised the manuscript for important intellectual content and was involved in the study supervision and coordination. GM was involved in developing the study concept and design, acquisition and interpretation of data, revised the manuscript for important intellectual content and was involved in the study supervision and coordination. CE was involved in developing the study concept and design, acquisition and interpretation of data, drafting of the manuscript, revised the manuscript for important intellectual content, lead the study supervision and coordination, obtained funding and is accountable for all aspects of the work. All authors read and approved the final version of the manuscript.

\section{Acknowledgment}

The Nigeria National Blindness and Visual Impairment Study Group also consisted of:

1. Abdullahi Imam. Ministry of Health, Minna, Niger State, Nigeria.

2. Adenike Abiose. International Agency for Prevention of Blindness, Africa

Region, Ibadan, Nigeria.

3. Christian Ezelum. Ministry of Health, Awka, Anambra State, Nigeria.

4. Hannah Faal. Africa Vision Research Institute, Durban, South Africa.

5. Mohammed M Abdull. Abubakar Tafawa Balewa University Teaching

Hospital, Bauchi, Nigeria.

6. Olufunmilayo O Bankole. Lions Eye Centre, Isolo General Hospital, Lagos

State, Nigeria.

7. Pak Sang Lee. Institute of Ophthalmology, University College London,

London, UK

8. Tafida Abubakar. Ministry of Health, Dutse, Jigawa State, Nigeria.

\section{Previous presentation}

Some information in this paper was presented in part at the World

Ophthalmology Conference (WOC), Abu Dhabi, February 2012.

\section{Data availability statement}

Data is currently with the authors as work is on-going but will be deposited at the Federal Ministry of Health, Nigeria:

Dr Ngozi R. C. Azodoh, Director; Health Planning, Research and Statistics,

Federal Ministry of Health, Abuja, Nigeria; Email address:

ngoziazodoh@yahoo.com.

\section{Sources of funding and financial support}

The Nigeria National Blindness and Visual Impairment Survey was supported by Sightsavers International (http://www.sightsavers.org/), CBM (http:// www.cbm.org/), Velux Stiftung (http://www.veluxstiftung.ch/home/ index.php) and the Nigeria Federal and State Governments in Nigeria. The data analysis and writing was supported by the Fred Hollows Foundation (http://www.hollows.org.au/) for FK.

Richard Wormald is funded in the UK by financial support from the Department of Health through the award made by the National Institute for Health Research to Moorfields Eye Hospital NHS Foundation Trust and UCL Institute of Ophthalmology for a Specialist Biomedical Research Centre for Ophthalmology.

The funding organizations had no role in the study design, conduct of this research, data analysis, decision to publish, or preparation of the manuscript.

\section{Author details}

'International Centre for Eye Health (ICEH), Clinical Research Department, London School of Hygiene and Tropical Medicine (LSHTM), Keppel Street, London WC1E 7HT, UK. ${ }^{2}$ Department of Ophthalmology, College of Health Sciences (CHS), University of Abuja, Abuja, Nigeria. ${ }^{3}$ Vision Health Services, Ikeja, Lagos State, Nigeria. ${ }^{4}$ Prevention of Blindness Union, Riyadh, Saudi Arabia. ${ }^{5}$ Bristol Eye Hospital, University Hospitals, Bristol NHS Foundation Trust, Bristol, UK. ${ }^{6}$ Moorfields Eye Hospital, London, United Kingdom. ' Indian Institute of Public Health, Public Health Foundation of India, Hyderabad, Andhra Pradesh, India.

Received: 2 July 2015 Accepted: 24 November 2015

Published online: 12 December 2015

\section{References}

1. Pascolini D, Mariotti SP. Global estimates of visual impairment: 2010. Br J Ophthalmol. 2012;96:614-8.

2. Cook C. Glaucoma in Africa: size of the problem and possible solutions. J Glaucoma. 2009;18:124-8.

3. Kyari F, Abdull MM, Bastawrous A, Gilbert CE, Faal H. Epidemiology of glaucoma in Sub-Saharan Africa: Prevalence, incidence and risk factors. Middle East Afr J Ophthalmol. 2013;20:111-25. 
4. Bastawrous A, Burgess PI, Mahdi AM, Kyari F, Burton MJ, Kuper H. Posterior segment eye disease in sub-Saharan Africa: review of recent populationbased studies. Trop Med Int Health. 2014;19:600-9.

5. Quigley HA, Broman AT. The number of people with glaucoma worldwide in 2010 and 2020. Br J Ophthalmol. 2006;90:262-7.

6. Tham YC, Li X, Wong TY, Quigley HA, Aung T, Cheng CY. Global Prevalence of Glaucoma and Projections of Glaucoma Burden through 2040: a systematic review and meta-analysis. Ophthalmology. 2014;121:2081-90.

7. Quigley HA. New paradigms in the mechanisms and management of glaucoma. Eye (Lond). 2005;19(12):1241-8.

8. Egbert PR. Glaucoma in West Africa: a neglected problem. Br J Ophthalmol. 2002:86:131-2.

9. Naidoo K, Gichuhi S, Basanez MG, Flaxman SR, Jonas JB, Keeffe J, et al. Prevalence and causes of vision loss in sub-Saharan Africa: 19902010. Br J Ophthalmol. 2014;98:612-8.

10. Kyari F, Gudlavalleti MV, Sivsubramaniam S, Gilbert CE, Abdull MM, Entekume G, et al. Prevalence of blindness and visual impairment in Nigeria: the National Blindness and Visual Impairment Study. Invest Ophthalmol Vis Sci. 2009;50:2033-9.

11. Abdull MM, Sivasubramaniam S, Murthy GV, Gilbert C, Tafida A, Ezelum C, et al. Causes of blindness and visual impairment in Nigeria: the Nigeria national blindness and visual impairment survey. Invest Ophthalmol Vis Sci. 2009:50:4114-20.

12. Entekume G, Patel J, Sivasubramaniam S, Gilbert CE, Ezelum CC, Murthy GVS, et al. Prevalence, causes, and risk factors for functional low vision in Nigeria: results from the national survey of blindness and visual impairment. Invest Ophthalmol Vis Sci. 2011;52:6714-9.

13. Foster PJ, Buhrmann R, Quigley HA, Johnson GJ. The definition and classification of glaucoma in prevalence surveys. $\mathrm{Br} J$ Ophthalmol. 2002;86:238-42.

14. Cheng JW, Cheng SW, Ma XY, Cai JP, Li Y, Wei RL. The prevalence of primary glaucoma in mainland China: a systematic review and metaanalysis. J Glaucoma. 2013;22:301-6.

15. Tielsch JM, Sommer A, Katz J, Royall RM, Quigley HA, Javitt J. Racial variations in the prevalence of primary open-angle glaucoma. The Baltimore Eye Survey. JAMA. 1991;266:369-74.

16. Mason RP, Kosoko O, Wilson MR, Martone JF, Cowan CL, Gear JC, et al. National survey $f$ the prevalence and risk factors of glaucoma in St. Lucia, West Indies. Part I. Prevalence findings. Ophthalmology. 1989;96:1363-8.

17. Leske MC, Connell AM, Schachat AP, Hyman L. The Barbados Eye Study. Prevalence of open angle glaucoma. Arch Ophthalmol. 1994;112:821-9.

18. Buhrmann RR, Quigley HA, Barron Y, West SK, Oliva MS, Mmbaga BB. Prevalence of glaucoma in a rural East African population. Invest Ophthalmol Vis Sci. 2000;41:40-8.

19. Rotchford AP, Johnson GJ. Glaucoma in Zulus: a population-based cross-sectional survey in a rural district in South Africa. Arch Ophthalmol. 2002;120:471-8.

20. Rotchford AP, Kirwan JF, Muller MA, Johnson GJ, Roux P. Temba glaucoma study: a population-based cross-sectional survey in urban South Africa. Ophthalmology. 2003;110:376-82.

21. Budenz DL, Barton K, Whiteside-de Vos J, Schiffman J, Bandi J, Nolan W, et al. Prevalence of Glaucoma in an Urban West African Population: the Tema Eye Survey. JAMA Ophthalmol. 2013;131:651-8.

22. Ashaye A, Ashaolu O, Komolafe O, Ajayi BGK, Olawoye O, Olusanya B, et al. Prevalence and types of glaucoma among an indigenous African population in southwestern Nigeria. Invest Ophthalmol Vis Sci. 2013;54: 7410-6.

23. Statistics | At a glance: Nigeria | UNICEF. Available at http://www.unicef.org/ infobycountry/nigeria_statistics.html.

24. Dineen B, Gilbert CE, Rabiu M, Kyari F, Mahdi AM, Abubakar T, et al. The Nigerian national blindness and visual impairment survey: Rationale, objectives and detailed methodology. BMC Ophthalmol. 2008:8:17.

25. Bourne RR, Rosser DA, Sukudom P, Dineen B, Laidlaw DA, Johnson GJ, et al. Evaluating a new logMAR chart designed to improve visual acuity assessment in population-based surveys. Eye (Lond). 2003;17: 754-8.

26. Van Herick W, Shaffer RN, Schwartz A. Estimation of width of angle of anterior chamber. Incidence and significance of the narrow angle. Am J Ophthalmol. 1969;68:626-9.

27. Patel SC, Friedman DS, Varadkar P, Robin AL. Algorithm for interpreting the results of frequency doubling perimetry. Am J Ophthalmol. 2000;129:323-7.
28. Zeppieri M, Johnson CA. Frequency Doubling Technology (FDT) perimetry. Imaging and Perimetry Society. Accessed 17 March 2015.

29. Kyari F, Abdull MM, Sallo FB, Spry PG, Wormald R, Peto T, et al. Nigeria normative data for defining glaucoma in prevalence surveys. Ophthalmic Epidemiol. 2015;22:98-108.

30. Gilbert CE, Murthy GV, Sivasubramaniam S, Kyari F, Imam A, Rabiu MM, et al. Couching in Nigeria: prevalence, risk factors and visual acuity outcomes. Ophthalmic Epidemiol. 2010;17:269-75.

31. Foster PJ, Oen FT, Machin D, Ng T, Devereux JG, Johnson GJ, et al. The prevalence of glaucoma in Chinese residents of Singapore: a cross-sectional population survey of the TanjongPagar district. Arch Ophthalmol. 2000;118: 1105-11.

32. Song W, Shan L, Cheng F, Fan P, Zhang L, Qu W, et al. Prevalence of glaucoma in a rural northern china adult population: a populationbased survey in Kailucounty, Inner Mongolia. Ophthalmology. 2011; 118:1982-8.

33. Thapa SS, Paudyal I, Khanal S, Twyana SN, Paudyal G, Gurung R, et al. A population-based survey of the prevalence and types of glaucoma in Nepal: the Bhaktapur Glaucoma Study. Ophthalmology. 2012;119:759-64.

34. Nangia V, Jonas JB, Matin A, Bhojwani K, Sinha A, Kulkarni M, et al. Prevalence and associated factors of glaucoma in rural central India. The Central India Eye and Medical Study. PLoS One. 2013;8, e76434.

35. Narayanaswamy A, Baskaran M, Zheng Y, Lavanya R, Wu R, Wong W, et al. The prevalence and types of glaucoma in an urban Indian population: the Singapore Indian Eye Study. Invest Ophthalmol Vis Sci. 2013;54:4621-7.

36. Shen SY, Wong TY, Foster PJ, Loo J, Rosman M, Loon S, et al. The prevalence and types of glaucoma in Malay people: the Singapore Malay eye study. Invest Ophthalmol Vis Sci. 2008;49:3846-51.

37. Wang $Y X, X u L$, Yang $H$, Jonas JB. Prevalence of glaucoma in North China: the Beijing Eye Study. Am J Ophthalmol. 2010;150:917-24.

38. Baskaran M, Foo RC, Cheng CY, Narayanaswamy AK, Zheng YF, Wu R, et al. The prevalence and types of glaucoma in an urban Chinese population: the Singapore Chinese Eye Study. JAMA ophthalmol. 2015. doi: 10.1001/ jamaophthalmol.2015.1110.

39. Klein BE, Klein R, Sponsel WE, Franke T, Cantor LB, Martone J, et al. Prevalence of glaucoma. The Beaver Dam Eye Study. Ophthalmology. 1992; 99:1499-504.

40. Weih LM, Nanjan M, McCarty CA, Taylor HR. Prevalence and predictors of open-angle glaucoma: results from the visual impairment project. Ophthalmology. 2001;108:1966-72.

41. Bonomi L, Marchini G, Marraffa M, Bernardi P, De Franco I, Perfetti S, et al. Prevalence of glaucoma and intraocular pressure distribution in a defined population. The Egna-Neumarkt Study. Ophthalmology. 1998;105:209-15.

42. Cedrone C, Culasso F, Cesareo M, Zapelloni A, Cedrone P, Cerulli L. Prevalence of glaucoma in Ponza, Italy: a comparison with other studies. Ophthalmic Epidemiol. 1997:4:59-72.

43. Dielemans I, Vingerling JR, Wolfs RC, Hofman A, Grobbee DE, de Jong PT. The prevalence of primary open-angle glaucoma in a population-based study in The Netherlands. The Rotterdam Study. Ophthalmology. 1994;101:1851-5.

44. Nizankowska MH, Kaczmarek R. Prevalence of glaucoma in the Wroclaw population. The Wroclaw epidemiological study. Ophthalmic Epidemiol. 2005;12:363-71.

45. Sakata K, Sakata LM, Sakata VM, Santini C, Hopker L, Bernardes R, et al. Prevalence of glaucoma in a South $<$ ? show [?A3B2 twb=.3w?]? $><$ ? show [?A3B2 tlsb=.09pt?]?>Brazilian population: Projeto Glaucoma. Invest Ophthalmol Vis Sci. 2007:48:4974-9.

46. Pakravan M, Yazdani S, Javadi MA, Amini H, Behroozi Z, Ziaei H, et al. A population-based survey of the prevalence and types of glaucoma in Central Iran: the Yazd eye study. Ophthalmology. 2013;120:1977-84.

47. Chua BE, Xie J, Arnold AL, Koukouras I, Keeffe JE, Taylor HR. Glaucoma prevalence in Indigenous Australians. Br J Ophthalmol. 2011;95:926-30

48. Al-Mansouri FA, Kanaan A, Gamra H, Khandekar R, Hashim SP, Al Qahtani O, et al. Prevalence and determinants of glaucoma in citizens of Qatar aged 40 years or older: a community-based survey. Middle East Afr J Ophthalmol. 2011:18:141-9.

49. Kosoko-Lasaki O, Gong G, Haynatzki G, Wilson MR. Race, ethnicity and prevalence of primary open-angle glaucoma. J Natl Med Assoc. 2006;98:1626-9.

50. Leske MC. Open-angle glaucoma - an epidemiologic overview. Ophthalmic Epidemiol. 2007;14:166-72. 
51. Rotimi CN, Chen G, Adeyemo AA, Jones LS, Agyenim-Boateng K, Eghan BA, et al. Genomewide scan and fine mapping of quantitative trait loci for intraocular pressure on $5 q$ and $14 q$ in West Africans. Invest Ophthalmol Vis Sci. 2006;47:3262-7.

52. Liu Y, Hauser MA, Akafo SK, Qin X, Miura S, Gibson JR, et al. Investigation of known genetic risk factors for primary open angle glaucoma in two populations of African ancestry. Invest Ophthalmol Vis Sci. 2013;54:6248-54.

53. Wilson R, Richardson TM, Hertzmark E, Grant WM. Race as a risk factor for progressive glaucomatous damage. Ann Ophthalmol. 1985;17:653-9.

54. Pache M, Flammer J. A sick eye in a sick body? Systemic findings in patients with primary open-angle glaucoma. Surv Ophthalmol. 2006;51:179-212.

55. Vohra R, Tsai JC, Kolko M. The role of inflammation in the pathogenesis of glaucoma. Surv Ophthalmol. 2013;58:311-20.

56. Nemesure B, Wu SY, Hennis A, Leske MC, Barbados Eye Study Group. Corneal thickness and intraocular pressure in the Barbados eye studies. Arch Ophthalmol. 2003;121:240-4.

57. Leske MC, Wu SY, Hennis A, Honkanen R, Nemesure B. Risk factors for incident open-angle glaucoma: the Barbados Eye Studies. Ophthalmology. 2008;115:85-93.

58. Parkin B, Shuttleworth G, Costen M, Davison C. A comparison of stereoscopic and monoscopic evaluation of optic disc topography using a digital optic disc stereo camera. Br J Ophthalmol. 2001;85:1347-51.

59. Morgan JE, Sheen NJ, North RV, Choong Y, Ansari E. Digital imaging of the optic nerve head: monoscopic and stereoscopic analysis. Br J Ophthalmol. 2005;89:879-84.

60. Kyari F. An ideal service for glaucoma would be.... Community Eye Health. 2014;27:52.

\section{Submit your next manuscript to BioMed Central and we will help you at every step:}

- We accept pre-submission inquiries

- Our selector tool helps you to find the most relevant journal

- We provide round the clock customer support

- Convenient online submission

- Thorough peer review

- Inclusion in PubMed and all major indexing services

- Maximum visibility for your research

Submit your manuscript at www.biomedcentral.com/submit
(O) BioMed Central 